\title{
Some Aerodynamic Considerations in the Design of Centrifugal Compressor Impellers
}

\author{
G. Gopalakrishnan* \\ *Professor Emeritus, Department of Mechanical Engineering, Dr. M.G.R Educational \& Research Institute, \\ Chennai, India
}

\begin{abstract}
A simple one dimensional approach to determine the size of the centrifugal impeller for maximum through flow has been indicated. This design procedure does not mean that the centrifugal impeller could be finally decided on the results obtained from this article.

It must be borne in mind that this only deals with some aspects of the design and in itself is not a complete one by which the impeller could have its final shape and size. The major idea of introducing this paper is to highlight the importance of some of the parameters that go towards influencing the design of the centrifugal impeller.

The stage pressure, temperature and work output of a centrifugal machine is basically dependant on the major dimensions like the diameter of the impeller ' $d 2$ ' and its tip speed ' $u 2$ ', the vane outlet angle ' $\beta 2$ ' and the flow coefficient ' $\varnothing 2$ ' at exit ' $c 2 \mathrm{~m} / \mathrm{u2}$ '.

Further, the influence of the inlet vane angle ' $\beta 1$ ' and the inlet Mach number ' $M 1$ 'of the flow seriously affect the design of the high speed centrifugal impeller. Some guidelines have been indicated.

The shape of the impeller channel passages are to be designed based on whether the compressor needs to have an energy build up in the impeller or a high pressure generation within the impeller of the compressor. In such cases, the radial diffuser at the exit of the impeller plays a very crucial role.

Since the speed at which the impeller rotates is of interest, it is absolutely necessary for the designer to pay attention to the stress calculations of the impeller rear and front shrouds.
\end{abstract}

\section{Nomenclature:}

$\boldsymbol{\alpha} \quad$ fluid angle

$\beta \quad$ vane, angle

$\delta \quad$ semi cone angle, boundary layer thickness

$\emptyset \quad$ flow coefficient $c_{m} / u_{2}$

$\rho \quad$ fluid density

$\sigma \quad$ Slip fctor

$\aleph, k \quad$ ratio of specific heats $c_{p} / c_{v}$

$\omega \quad$ angular velocity Type equation here.

a, A constants, annulus area, area, velocity of sound

$b, b l, B$ vane height, blade

$c \quad$ absolute velocity

$c_{p} \quad$ Specific heat at constant pressure

$c_{v} \quad$ Specific heat at constant volumeN

$h \quad$ vane height

$k \quad$ ratio of specific heats $c_{p} / c_{v}$

m, $M \quad$ mas flow, Mach no.

$n \quad$ distance normal to streamline

$p \quad$ static pressure

$r, R \quad$ radius

$t_{1}, t, T$ time, temperature

$V \quad$ volume flow rate

$w, W \quad$ relative velocity, Specific work

$X \quad$ coordinate direction, linear length

$y, Y \quad$ coordinate direction

$z \quad$ coordinate direction, number of vanes

\section{Subscripts}

- average

$-\quad$ first differentiation with reference to $x$ 


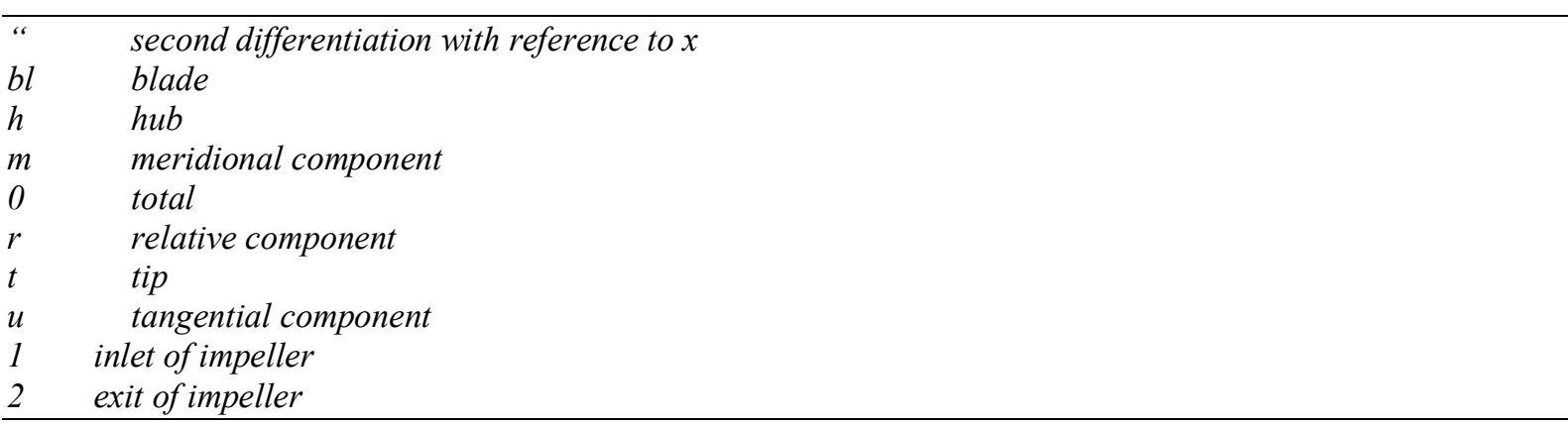

\section{Introduction}

A matter of timely concern is the harvesting of solar energy. In this aspect the smaller gas turbines are being sought after. The centrifugal compressor comes in as a good competitor to the axial flow machine, in that, compared to its axial counterpart, it is easier to produce and more compact. Of immediate concern is the development and design of the small compact compressors of high efficiency. Efficiencies of larger machines are of the order of $85 \%-95 \%$; but however in the case of the smaller machines it becomes difficult in having matching diffusers for the highly efficient impeller.

Large amount of theoretical work have been reported widely across the globe; with both the RANS (Reynolds Navier Stokes) and CFD techniques suggesting improved design methods. The separation of the fluid on the suction side of the impeller vanes has been for long posing diffuser matching problems. Secondary flows in the impeller channels have been troubling aerodynamic calculations of the system. Splitter vanes and boundary layer fences have also been tried with little improvement.

Pfleiderer was the first perhaps, to enunciate the maintenance of the inlet angle of the impeller vanes to be $34 \mathrm{deg}$. to avoid shocks at inlet to the impeller.

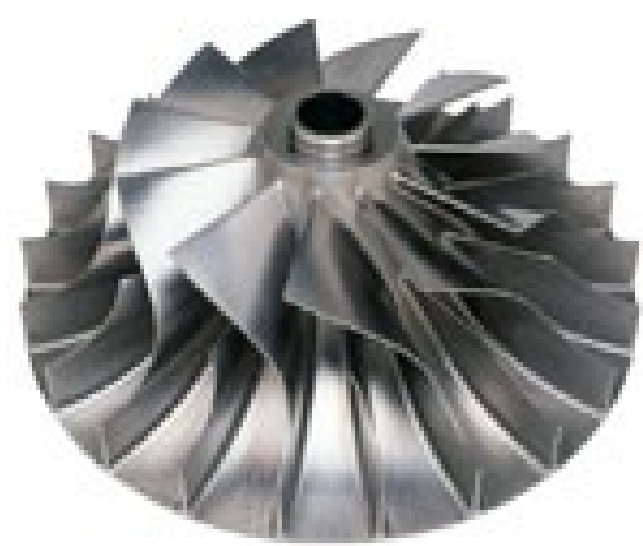

Fig. 1 Centrifugal Compressor Impeller

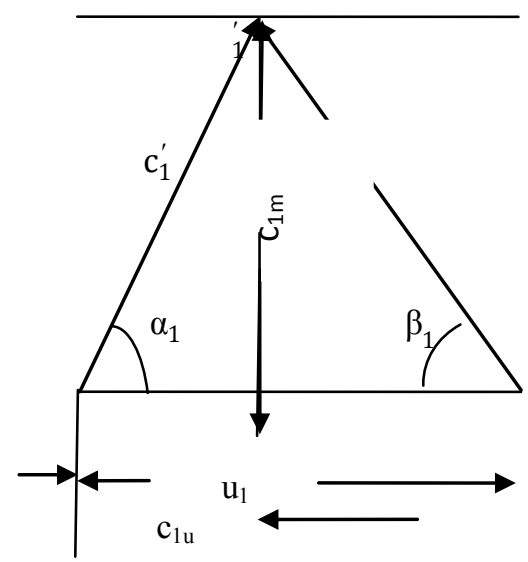


Fig. 2 Velocity Triangle at Inlet to Impeller

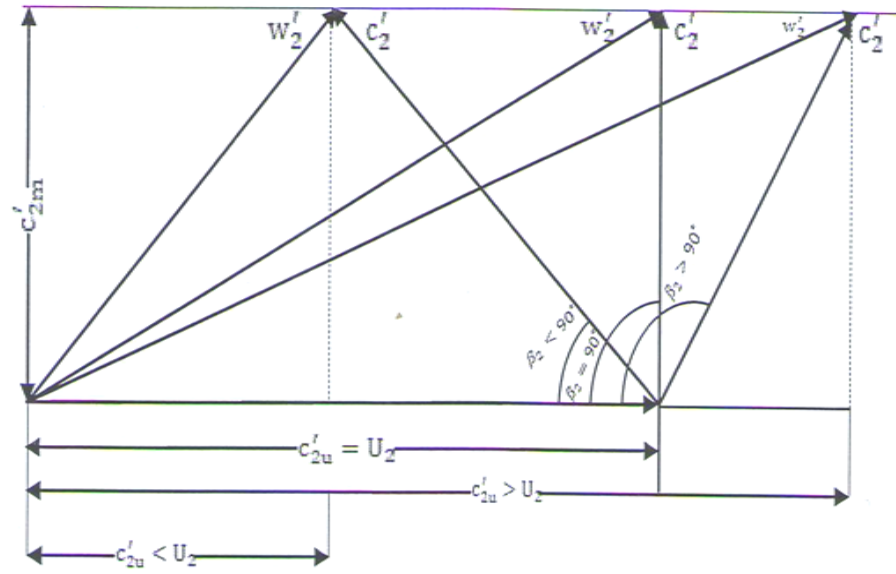

Fig. 3 Velocity Triangles at Exit of Impeller

Stanitz using relaxation methods to analyze the non-viscous two dimensional through -flow through radial and logarithmic spiral vaned impellers arrived at an equation similar to Stodola's $\sigma$

$\sigma=1-\frac{0.63 \pi \sin \beta_{2}^{\prime}}{\mathrm{z}\left[1-\emptyset_{2} \cot \beta_{2}^{\prime}\right]}$

Stanitz further observed that slip is unaffected by changes in impeller tip speed and compressibility, while for an impeller with constant cone angle, slip is only a function of the number of vanes.

\section{Influence of Impeller Vane Exit Angle}

It has been shown, that the energy transfer in a turbomachine impeller is essentially dependent on the magnitude of $u_{2}$ and $c_{2 u}$ for a given impeller tip speed, the blade specific work, $W_{b l}$ is proportional to $c_{2 u}$ and therefore a function of $\beta_{2}$

$$
\mathrm{W}_{\mathrm{bl}}=\mathrm{u}_{2} \mathrm{c}_{2 \mathrm{u}}-\mathrm{u}_{1} \mathrm{c}_{1 \mathrm{u}}
$$

In the absence of prewhirl, i.e

$$
\begin{aligned}
& \alpha_{1}=90^{\circ}, \text { or } \mathrm{c}_{1 \mathrm{u}}=0, \\
& \mathrm{~W}_{\mathrm{bl}}=\mathrm{u}_{2} \mathrm{c}_{2 \mathrm{u}}
\end{aligned}
$$

(3)

$$
\begin{gathered}
=\mathrm{u}_{2}\left[\mathrm{u}_{2}-\mathrm{c}_{2 \mathrm{~m}} / \tan \beta_{2}\right] \\
\mathrm{u}_{2}=\frac{\mathrm{c}_{2 \mathrm{~m}}}{2 \tan \beta_{2}} \pm \sqrt{\left[\frac{\mathrm{c}_{2 \mathrm{~m}}}{2 \tan \beta_{2}}\right]^{2}+\mathrm{W}_{\mathrm{bl}}}
\end{gathered}
$$

more generally,

$$
\mathrm{u}_{2}=\frac{\mathrm{c}_{2 \mathrm{~m}}}{2 \tan \beta_{2}} \pm \sqrt{\left[\frac{\mathrm{c}_{2 \mathrm{~m}}}{2 \tan \beta_{2}}\right]+\mathrm{W}_{\mathrm{bl}}+\mathrm{u}_{1} \mathrm{c}_{1 \mathrm{u}}}
$$

As a consequence of Eqn. (4) it can be shown that the energy transfer per stage is primarily a function of $\mathrm{u}_{2}, \mathrm{c}_{2 \mathrm{~m}}$ and $\beta_{2}$

Fig.(4) shows the three types of impellers with different vane angles $\beta_{2}^{\prime}$. It should be borne in mind that this $\beta_{2}$ is the fluid angle at vane exit. An impeller with a backward swept vane $\left(\beta_{2}^{\prime}<90^{\circ}\right)$ would have a falling characteristic, a radial vane $\left(\beta_{2}^{\prime}=90^{\circ}\right)$ would have a level characteristic and that with a forward swept vane $\left(\beta_{2}^{\prime}>90^{\circ}\right)$ an increasing characteristic. It can also be explained with the help of Eqn (6) that for a given speed ' $n$ ', the size of the impeller would increase as $\beta_{2}^{\prime}$ decreases. 

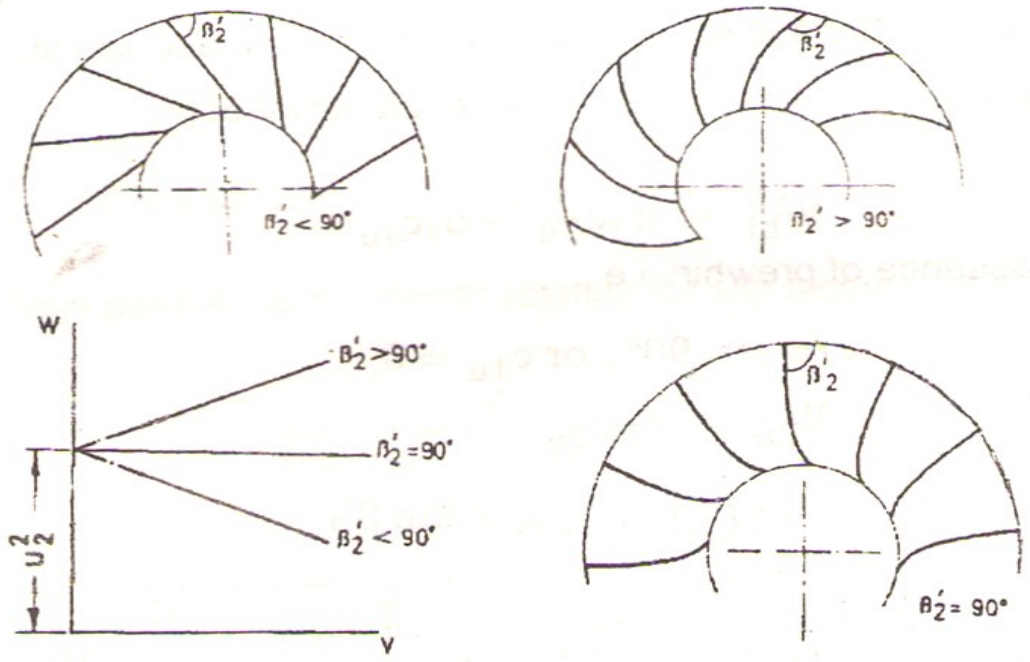

Fig. 4 Types of Vane Profiles

\section{One Dimensional Considerations for Maximum Through -Flow}

The desired maximum capacity of a centrifugal machine is mostly dependent on the maximum inlet area that could be provided. At higher speeds and capacities the performance of centrifugal impellers decay rather rapidly due to the formation of compression shocks. The inducer is the most important component that needs to be designed very carefully to avoid Mach number peaks at impeller inlet. An inducer imparts a solid body rotation to the fluid at inlet.

Assuming an uniform inlet velocity distribution namely, $\mathrm{c}_{1 \mathrm{~m}} \neq \mathrm{f}(\mathrm{r})$, and the flow to be compressible, then the volume flow at inlet could be represented as

$\mathrm{V}=\mathrm{c}_{1 \mathrm{~m}} \cdot \mathrm{A}_{1}=\mathrm{c}_{1 \mathrm{~m}} \cdot \pi\left\{\mathrm{r}_{\mathrm{lt}}^{2}-\mathrm{r}_{\mathrm{lh}}^{2}\right\}$

$\mathrm{c}_{1 \mathrm{~m}}=\left[\mathrm{w}_{\mathrm{lt}}^{2}-\omega^{2} \mathrm{r}_{\mathrm{lt}}^{2}\right]^{1 / 2}$ when $\mathrm{c}_{\mathrm{lu}}=0$

$\mathrm{V}=\pi\left[\mathrm{r}_{\mathrm{lt}}^{2}-\mathrm{r}_{\mathrm{lh}}^{2}\right]\left[\mathrm{w}_{\mathrm{lt}}^{2}-\omega^{2} \cdot \mathrm{r}_{\mathrm{lt}}^{2}\right]^{1 / 2}$

Differentiating Eqn.(9) w.r.t. ' $\mathrm{r}_{1 \mathrm{t}}$ ' and equating to zero for maximum volume rate of flow,

$\frac{1}{\pi} \frac{\partial \mathrm{V}}{\partial \mathrm{r}_{1 \mathrm{t}}}=2 \cdot \mathrm{r}_{1 \mathrm{t}}\left[\mathrm{w}_{\mathrm{lt}}^{2}-\omega^{2} \cdot \mathrm{r}_{\mathrm{lt}}^{2}\right]^{1 / 2}-\frac{\omega^{2} \mathrm{r}_{1 \mathrm{t}}\left(\mathrm{r}_{1 \mathrm{t}}^{2}-\mathrm{r}_{1 \mathrm{~h}}^{2}\right)}{\left(\mathrm{w}_{\mathrm{lt}}^{2}-\omega^{2} \cdot \mathrm{r}_{\mathrm{lt}}^{2}\right)}=0$

$\mathrm{w}_{\mathrm{lt}}^{2}=\omega^{2}\left[1.5 \mathrm{r}_{1 \mathrm{t}}^{2}-0.5 \mathrm{r}_{1 \mathrm{~h}}^{2}\right]$

so that, $\tan \beta_{1 \mathrm{t}}=\frac{\mathrm{c}_{1 \mathrm{~m}}}{\mathrm{u}_{1 \mathrm{t}}}=0.5\left[1-\left[\mathrm{r}_{1 \mathrm{~h}} / \mathrm{r}_{1 \mathrm{t}}\right]^{2}\right]^{1 / 2}$

on the other hand, if the flow is assumed to be compressible,

$$
\begin{aligned}
\mathrm{m} & =\mathrm{A}_{1} \cdot \mathrm{c}_{1} \cdot \rho_{1} \text {, when } \mathrm{c}_{1 \mathrm{u}}=0, \mathrm{c}_{1 \mathrm{~m}}=\mathrm{c}_{1} \\
& =\mathrm{A}_{1} \cdot \rho_{0} \cdot \mathrm{a}_{0} \cdot \mathrm{M}_{1} \cdot \frac{\rho_{1 \cdot \mathrm{a}_{1}}}{\rho_{0 . \mathrm{a}_{0}}} \\
& =\pi \cdot \mathrm{r}_{1 \mathrm{t}}^{2} \cdot\left[1-\left(\frac{\mathrm{r}_{1 \mathrm{~h}}}{\mathrm{r}_{1 \mathrm{t}}}\right)^{2}\right] \cdot \rho_{0}, \mathrm{a}_{0} \cdot \mathrm{M}_{1} \cdot\left[1+\frac{\mathrm{k}-1}{2} \mathrm{M}_{1}^{2}\right]^{-(\mathrm{k}+1) / 2(\mathrm{k}-1)}
\end{aligned}
$$

Where

$$
\begin{aligned}
& \mathrm{A}_{1}=\pi \cdot \mathrm{r}_{1 \mathrm{t}}^{2} \cdot\left[1-\left(\frac{\mathrm{r}_{1 \mathrm{~h}}}{\mathrm{r}_{1 \mathrm{t}}}\right)^{2}\right] \\
& \frac{\rho_{1 . \mathrm{a}_{1}}}{\rho_{0 . \mathrm{a}_{0}}}=\left[\frac{\mathrm{T}_{1}}{\mathrm{~T}_{0}}\right]^{1 / \mathrm{k}-1} \cdot\left[\frac{\mathrm{T}_{1}}{\mathrm{~T}_{0}}\right]^{1 / 2} \\
& \quad=\left[1+\frac{\mathrm{k}-1}{2} \mathrm{M}_{1}^{2}\right]^{-(\mathrm{k}+1) / 2(\mathrm{k}-1)} \\
& \frac{\mathrm{r}_{1 \mathrm{t}}}{\mathrm{r}_{2}}=\frac{\mathrm{M}_{1 \mathrm{rt}} \cos \beta_{1 \mathrm{t}}}{\mathrm{u}_{2} / \mathrm{a}_{0}} \cdot\left[1+\frac{\mathrm{k}-1}{2} \mathrm{M}_{1}^{2}\right]^{-1 / 2} \\
& \frac{\mathrm{m}}{\rho_{0} \mathrm{a}_{0} \pi}\left[\frac{\mathrm{u}_{2}}{\mathrm{a}_{0}}\right]=\left[1-\left\{\mathrm{r}_{1 \mathrm{~h}} / \mathrm{r}_{1 \mathrm{t}}\right\}^{2}\right] \cdot \mathrm{r}_{2}^{2}\left\{\frac{\mathrm{M}_{1}\left[\mathrm{M}_{1 \mathrm{rt}} \cdot \cos \beta_{1 \mathrm{t}}\right]^{2}}{\left[1+\frac{\mathrm{k}-1}{2} \mathrm{M}_{1}^{2}\right]^{(3 \mathrm{k}-1) / 2(\mathrm{k}-1)}}\right\}
\end{aligned}
$$

The mass flow is a maximum when the right hand side of Eqn.(15) becomes maximum.

Fig. (5) shows the Variation of inlet Mach no. as a function of Vane Inlet Angle and Inlet Relative Mach No 


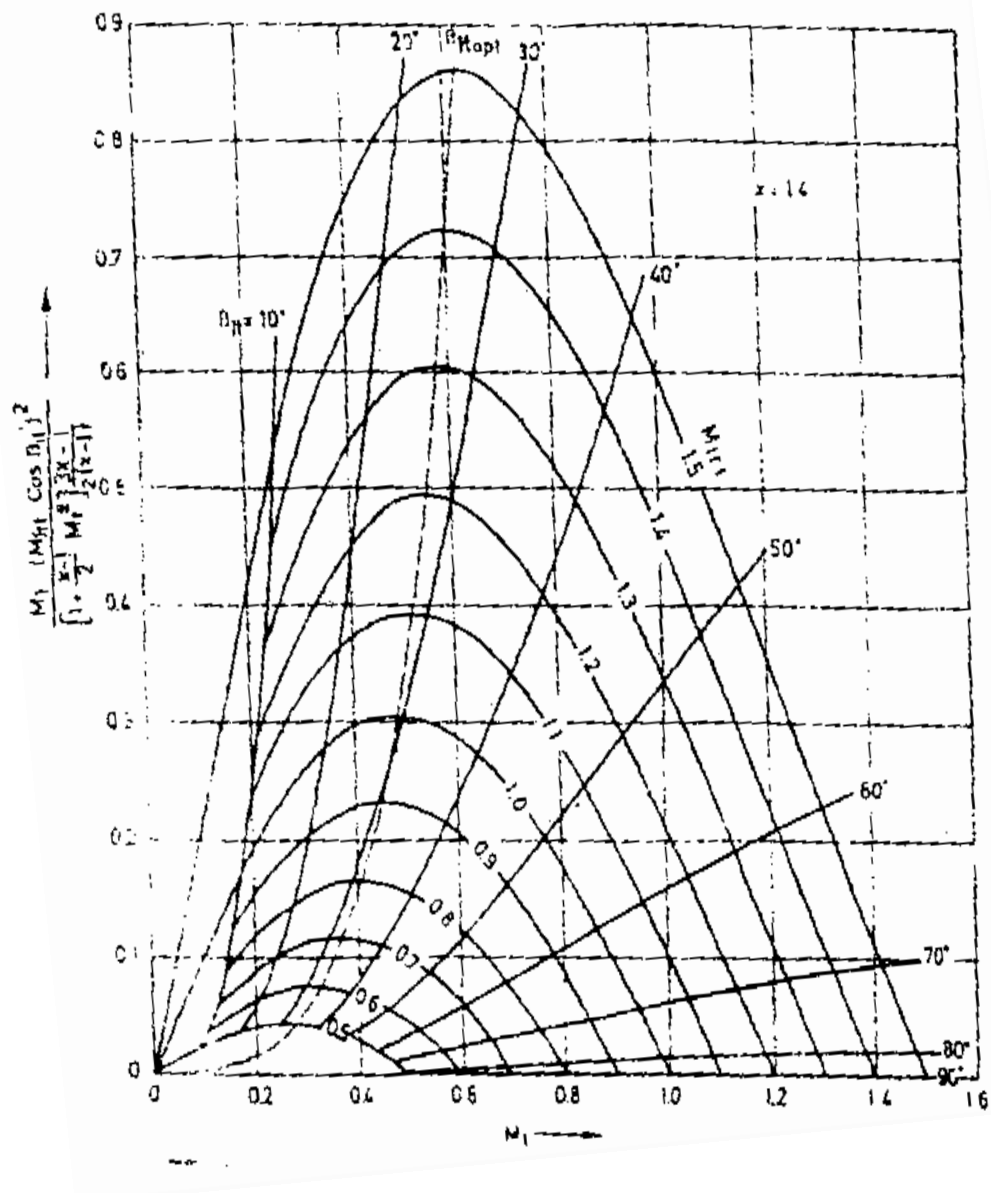

Fig. 5 Variation of inlet Mach no. as a function of Vane Inlet Angle and Inlet Relative Mach No

\section{Stage temperature rise}

The blade specific work per stage is given by

$$
\begin{aligned}
& \mathrm{W}_{\mathrm{bl}}=\mathrm{u}_{2} \mathrm{c}_{2 \mathrm{u}}-\mathrm{u}_{1} \mathrm{c}_{1 \mathrm{u}} \\
& =\operatorname{cp}\left(\mathrm{T}_{02}-\mathrm{T}_{01}\right)
\end{aligned}
$$

so that $\frac{\mathrm{T}_{02}-\mathrm{T}_{01}}{\mathrm{~T}_{01}}=\frac{\mathrm{u}_{2}^{2}}{\mathrm{c}_{\mathrm{p}} \mathrm{T}_{01}}\left[\frac{\mathrm{c}_{2 \mathrm{u}}}{\mathrm{u}_{2}}-\left[\frac{\mathrm{r}_{1}}{r_{2}}\right] \frac{\mathrm{c}_{1 \mathrm{u}}}{\mathrm{u}_{1}}\right]$

The sonic velocity referred to inlet stagnation conditions is given by $a_{01}^{2}=(k-1) \cdot c_{p} \cdot T_{01}$

Hence,

$\frac{\mathrm{T}_{02}-\mathrm{T}_{01}}{\mathrm{~T}_{01}}=[\mathrm{k}-1] \cdot\left[\frac{\mathrm{u}_{2}}{\mathrm{a}_{01}}\right]^{2}\left[\frac{\mathrm{c}_{2} \mathrm{u}}{\mathrm{u}_{2}}-\left[\frac{\mathrm{r}_{1}}{\mathrm{r}_{2}}\right]^{2} \frac{\mathrm{c}_{1} \mathrm{u}}{\mathrm{u}_{1}}\right]$

with no inlet prewhirl, the stage signation temperature rise is essentially a function of the impeller tip speed and slip. The ratio $\left[\mathrm{u}_{2} / \mathrm{a}_{\mathrm{o} 1}\right]$ is termed the 'Mach Index' of the stage, and denoted as ' $\pi_{\mathrm{m}}$ '.

\section{Mach number at impeller exit}

The absolute Mach number at impeller exit can be expressed as

$$
\begin{aligned}
\mathrm{M}_{2}^{2} & =\frac{\mathrm{c}_{2}^{2}}{\mathrm{kRT}_{2}} \\
& =\frac{\mathrm{c}_{2}^{2}}{\mathrm{~T}_{\mathrm{o} 1}} \cdot \frac{\mathrm{T}_{\mathrm{o} 1}}{\mathrm{~T}_{\mathrm{o} 2}} \cdot \frac{1}{\mathrm{kR}} \\
\frac{\mathrm{c}_{2}^{2}}{\mathrm{~T}_{\mathrm{o} 1}} & =\left[\emptyset_{2}^{2}+\left[1-\frac{\emptyset_{2}}{\tan \beta_{2}^{\prime}}\right] \cdot \frac{\mathrm{u}_{2}^{2}}{\mathrm{~T}_{01}}\right. \\
\frac{\mathrm{T}_{2}}{\mathrm{~T}_{01}} & =\left[1+\frac{\Delta \mathrm{T}_{\mathrm{o}}}{\mathrm{T}_{01}}-\frac{\mathrm{c}_{2}^{2}}{2 \mathrm{c}_{\mathrm{p}} \mathrm{T}_{01}}\right]
\end{aligned}
$$


Therefore, $M_{2}=f\left[\frac{\Delta T_{0}}{T_{01}}, \emptyset_{2}, \beta_{2}, c_{p}\right]$

The absolute impeller Mach number is therefore for a given media, a function of the flow co-efficient and the vane angle at exit.

\section{Stage Pressure Rise}

The stage temperature rise

$\left[\mathrm{T}_{03}-\mathrm{T}_{01}\right]=\eta_{1}\left[\mathrm{~T}_{02}-\mathrm{T}_{01}\right]$

$\left[\mathrm{T}_{02}-\mathrm{T}_{01}\right]=\eta_{1} \cdot \sigma \cdot \mathrm{u}_{2}^{2} / \mathrm{c}_{\mathrm{p}}$

$\frac{\mathrm{P}_{02}}{\mathrm{P}_{01}}=\left(\frac{\mathrm{T}_{03}}{\mathrm{~T}_{01}}\right)^{\frac{\mathrm{K}}{\mathrm{K}-1}}$

$$
=\left[1+\eta_{1} \cdot \sigma \cdot u_{2}^{2} / c_{p} T_{01}\right]
$$

Eqn.(25) necessarily implies that the blade tip speed of a high pressure ratio centrifugal compressor must be high and if non-radial, the vanes would be subjected to large bending stresses as a result of centrifugal forces.

\section{Acknowledgement}

The author is grateful to the management of Dr. M. G. R. Educational and Research Institute, for having permitted the author to publish this paper.

\section{References}

[1]. Bhargava, R K \& Gopalakrishnan, G (1978) Optimising Splitter Vane Locations Using the Method of Singularities, Proc. of the First International Conference on Centrifugal Compressor Technology, IIT, Madras, India

[2]. Fabri, J (1978) Flow Distribution in a Radial Impeller with Splitter Vanes, Proc. of the First International Conference on Centrifugal Compressor Technology, IIT, Madras, India149 -155

[3]. Ogawa, T \& Gopalakrishnan, G (1981) Use of Splitter Vanes in Centrifugal Compressor Impellers, Proc. Of the Eighth Canadian Congress of Applied Mechanics, Moncton, Canada

[4]. Gopalakrishnan, G (1974) Some Aerodynamic Aspects of Centrifugal Impeller Channel Flow, Ph.D. Thesis, Indian Institute of Technology, Madras, India

[5]. Gopalakrishnan, G \& Rangaswamy, C (1974) Influence of Prewhirl on Centrifugal Impeller Performance, Jl. of Instn. Of Engrs(I), vol.55,Pt. ME, pp.1-4

[6]. Gopalakrishnan, G \& Nagpurwala, Q H (1974) Freely Rotating Cambered Inlet Guide Vanes for Centrifugal Impellers, Jl. of Instn. Of Engrs(I), vol.55,Pt. ME, pp. 51-55

[7]. Pfleiderer, C und Petermann, H (2005) Strömungsmaschinen, 7. Auflage, Springer Verlag, Berlin

[8]. Stanitz, J D (1952) Some Theoretical Aerodynamic Investigations of Impellers in Radial and Mixed Flow Centrifugal Compressors, Trans. ASME, 74, Pp. 473

[9]. Stodola, A (1927) Steam and Gas Turbines, McGraw Hill Book Co. New York

[10]. Oana, M Kawamoto, O Ohtani, H \& Yamamoto, Y (2002) Approach to High Performance Transonic Centrifugal Compressor, AIAA paper 2002-3536

[11]. Hill, P \& Peterson, C (1992) Mechanics and Thermodynamics of Propulsion, 2nd Ed. Addison-Wesley Publishing Co., Reading, Mass. pp. 309-318

[12]. Fister, W(1963) Versuche zur Erfassung der Stromungsverhaltnisse an Radiallaufradern, Sonderdruck aus Triebwerks Aerodynamik der Turbomaschinen -Teil II: Radialmaschinen, Forschungsbericht der Aerodynamischen Versuchsanstalt, Gottingen Nr. 63-01S. 106-129

[13]. Majumdar, A K \& Spalding, D B (1978) Numerical Computation of Three Dimensional flows in a Rotating Curved Passage, Proc Of the First International Conference on Centrifugal Compressor Technology, IIT, Madras, India

[14]. Mizuki, S Ariga, J \& Watanabe, I (1975) A Study on the Flow Mechanism within Centrifugal Impeller Channels, ASME Paper 75 GT-14

[15]. Gallus, H E \& Subramanian, S (1978) Experimental Investigations to Reduce Wakes in Centrifugal Machines, Proc. Of the First International Conference on Centrifugal Compressor Technology, IIT, Madras, India

[16]. Pfleiderer, C und Petermann, H (2005) Strömungsmaschinen, 7. Auflage, Springer Verlag,Berlin,

[17]. Gopalakrishnan G \& Prithvi Raj D (2006) A Treatise on Turbomachines, $3^{\text {rd }}$ Edn, SCITECH Publications (I). Chennai

[18]. Gallus, H E (1978) Turbomachines - Lectures, RWTH Aachen, Germany

[19]. Ferguson, TB (1983) The Centrifugal Compressor Stage, Butterworths, London 